\title{
PRODUÇÃO E DISSEMINAÇÃO DE INFORMAÇÕES SOCIOECONÔMICAS
}

\author{
Osvaldo Guizzardi FILHO e \\ Vivaldo Luiz CONTI ${ }^{1}$
}

\begin{abstract}
RESUMO
$O$ artigo analisa, em primeiro lugar, a importância da informação para a geração do conhecimento e o papel e as especificidades das estatísticas socioeconômicas nesse processo. A seguir apresenta a forma como a produção dessas estatísticas está organizada e as mais significativas e recentes transformações pelas quais ela passou nas duas principais agências públicas dessa área, no pais, o IBGE e a Fundação Seade. Aborda também a questão dos diferentes padrões de financiamento nelas existentes e os motivos pelos quais eles foram adotados. Na sua parte final discute a questão da disseminação desde o modelo vigente antes dos advento da Internet, os impactos da revolução tecnológica e os novos desafios decorrentes da mudança no modelo de financiamento.
\end{abstract}

Palavras-chave: informação estatística; internet; custo da informação.

\begin{abstract}
The article analysis, in first place, the importance of information for knowledge generation and the role and specificities of social-economic statistics in this process. The following presents how the production of these statistics is organized and the most important and recent transformations of which it went through the two main public agencies of this area in the country: the IBGE and Seade Foundation. It also deals with the issue of different standards of financing existent and the motives of why they were adopted. In the final part, it discusses the issue of dissemination from the model existent before Internet, the impact of technological revolution and the new challenges deriving from the changes of the financing model.
\end{abstract}

Key words: statistical information; internet; information cost.

\section{INTRODUÇÃO}

Este artigo trata do produzir e disseminar uma categoria especial de informação, as estatísticas socioeconômicas. Estas permitem um enfoque bastante particular da realidade que nos cerca, contribuindo para seu conhecimento e para sua transformação. Mas do que estamos falando quando nos referimos à informação? Em que contexto ela deve ser entendida? Entendemos a informação como um insumo elementar para a atuação do ser humano no meio ambiente que o cerca. É trabalhando, analisando, acumulando e circulando a informação ao longo de sua história que o homem foi sendo capaz de produzir o conhecimento necessário para refletir sobre sua inserção no mundo, para pensar e dominar

1. Analistas de Projeto Sr. da Fundação Seade. As opiniões expressas neste artigo representam os pontos de vista pessoais dos autores. 
a natureza em seu próprio proveito. De acordo com Aldo Barreto:

"Contudo, são as definições - que relacionam a informação à produção de conhecimento no individuo - as que melhor explicam a natureza do fenômeno, em termos finalistas, associando-o ao desenvolvimento è à liberdade do indivíduo, de seu grupo de convivênciae da sociedade como um todo. Aqui a informação é qualificada como um instrumento modificador da consciência do homem e de seu grupo." (Barreto, 1994, p. 3).

Ao longo dos últimos anos, a humanidade vem assistindo a progressos na produção e na transmissão da informação e na geração e aplicação do conhecimento que, há algumas décadas atrás, seriam inimagináveis. Avanços e saltos constantes e acelerados na informática, nas telecomunicações, na indústria eletro-eletrônica e nos serviços de informação e comunicação vêm possibilitando ao homem um contato quase que alucinante com um fluxo imenso de informações que lhe chegam nas mais diferentes formas e através dos mais diferentes meios. Nesse contexto, noções como as de tempo e de espaço tornam-se fluidas, o acesso à informação gerada em qualquer parte do mundo é praticamente imediato. Este fato vem dando origem a uma verdadeira revolução. A informação, de maneira insidiosa, quando não temos plena consciência de que a estamos recebendo, ou quando a buscamos voluntariamente, transforma as mentes, potencializa o conhecimento, muda a forma de interação das pessoas consigo mesmas, com o ambiente em torno delas, com a sociedade.

Avanços tecnológicos como o rádio, a televisão e, mais recentemente, a Internet, permitiram que a informação circulasse de maneira cada vez mais fluida, mudando comportamentos arraigados, sacudindo organizações, modificando para melhor ou para pior, na dependência da opinião do observador,as relações entre as pessoas e as instituições. Os desenvolvimentos que são continuamente observados desde a segunda metade do século passado na chamada tecnologia da informação, com avanços que vão sendo alcançados quase que dia-a-dia na microinformática e nas telecomunicações, permitem que volumes cada vez maiores e mais diversificados de informações circulem com rapidez entre indivíduos e organizações, fornecendo elementos para que decisões sejam tomadas com maior grau de segurança.

Segundo SENRA (2000, p.2):

"Tal é sua importância que a informação chega mesmo a nomear a sociedade pós-industrial, expressando mudanças de fundo na vida econômica, marcada por um novo modo de produção, no qual muda a própria origem da riqueza. Assim, se na sociedade industrial o trabalho e o capital foram os fatores básicos da produção, na sociedade pós-industrial o fator básico da produção seria o conhecimento, de modo que a 'teoria do valor trabalho', formulada na economia clássica, cederia lugar a uma 'teoria do valor conhecimento' (ainda por ser compreendida)."

Hoje, através do microcomputador - e já também do telefone celular, da televisão a cabo, do aparelho de videogame - podemos caminhar por uma trilha que vai se desdobrando à nossa frente de forma praticamente infinita: num momento estamos visitando o acervo de um museu no Egito, no seguinte consultamos as manchetes de um jornal francês, num salto podemos escutar a programação de uma rádio manauara. Podemos também, por meio da Internet, ser colocados diretamente em contato com informação especializada em sites de revistas de divulgação científica ou de órgãos de pesquisa públicos e privados. Um dos tipos de informação que fornecem o suporte para a ação, principalmente, de empresas e governos é a estatística socioeconômica, que busca expressar, sob a forma de números, 
de agregados, determinadas facetas tidas, na visão de que as está elaborando, como as mais relevantes capazes de explicar uma dada realidade.

Para Maria Rosa Porcaro (2001, p.2).

"Considera-se que as estatísticas são representações numéricas da realidade a qual buscam mensurar. Em seu processo de construção, apoiam-se em interpretações teóricas que modelam aspectos da realidade e passam a criar seus próprios modelos de interpretação do real. As estatísticas que buscam apreender a realidade social guardam, pois, em sua configuração numérica, uma certa visão do mundo, o que as restringe ao contexto que as referencia."

Produzir estatísticas significa compartimentar o mundo, dividi-lo em categorias que o tornem compreensível, pelo menos a partir do ponto de vista dos especialistas que definem, por exemplo, a metodologia de uma determinada pesquisa, cujos resultados deverão espelhar os aspectos da realidade que se procura caracterizar. As estatísticas socioeconômicas resultam de um processo especializado de concepção e produção. Seu alcance, em termos das parcelas da sociedade que têm condições de utilizá-las, explorando ao máximo suas potencialidades, pode ser considerado limitado, originando-se esses usuários de círculos também bastante especializados: estudantes, pesquisadores, administradores públicos, empresas de consultoria.

Usá-las significa levar em consideração não só seu poder explicativo, mas também seus limites, 0 que coloca um grande desafio para aqueles que são responsáveis por sua produção e disseminação, e que precisam estar o tempo todo atentos para a necessidade de que também sejam divulgados conceitos, metodologias, procedimentos utilizados no levantamento das informações, possibilidades de sua utilização, para que delas se possa extrair o melhor e para que se amplie seu emprego pela população.
Essas informações resultam, em sua grande maioria, de pesquisas que são realizadas por instituições públicas especializadas. Têm sua origem também em levantamentos feitos por organismos privados de pesquisa e por instituições de representação de classes, podendo resultar ainda dos chamados registros administrativos, mantidos por empresas e órgãos públicos para a documentação de suas atividades ou para o acompanhamento dos movimentos da população, como ocorre com os cartórios de registro civil, onde são anotados os nascimentos, óbitos e casamentos. Esses registros, quando devidamente trabalhados e analisados, podem fornecer pistas importantes sobre, por exemplo, o comportamento da produção e sua distribuição espacial. Exemplos desses registros são os referentes à arrecadação de impostos, produção e consumo de água e energia elétrica, movimento do registro civil, vendas de derivados de petróleo, produção e vendas de material de embalagem.

No Brasil, na área pública, a instituição responsável pela produção das estatísticas nacionais é a Fundação Instituto Brasileiro de Geografia e Estatística - IBGE, que responde, inclusive, pela coordenação do Sistema Nacional de Estatística. O IBGE foi criado em 29 de maio de 1936, quando foi instalado o Instituto Nacional de Estatística, que passou a chamar-se Instituto Brasileiro de Geografia e Estatística em 26 de janeiro de 1938, com a promulgação do Decreto Lei $n^{\circ} 218$. Ele é o sucessor da Diretoria Geral de Estatística, que foi instituída, ainda no império, em 1871. Os Estados também contam com agências especializadas, variando muito seus portes e a gama de informações levantadas, processadas e analisadas em cada uma delas.

Como já foi dito, as estatísticas socioeconômicas resultam, em grande parte, de pesquisas que são específicamente construídas para esse fim. Ao longo de sua história, as agências de estatísticas foram desenvolvendo e se apropriando de ferramentais cada vez mais sofisticados para a realização dessas pesquisas, o que permite que elas sejam efetuadas hoje com menores custos - embora estes sejam ainda bastante 
significativos - e com maior agilidade na divulgação de seus resultados. Estas pesquisas podem ser censitárias ou amostrais.

No Brasil, atualmente, os Censos, que pressupõem o levantamento de informações sobre todos os indivíduos do universo que está sendo focalizado, são realizados, em primeiro lugar, para a caracterização da população: são os Demográficos, levados a campo, normalmente, a cada dez anos, tendo sido o último realizado em 2000 - o primeiro ocorreu em 1872, ano seguinte ao da criação da Diretoria Geral de Estatística. Cabe aqui observar que, excepcionalmente em 1996, entre dois Censos Demográficos, o órgão nacional de estatística efetuou a Contagem da População, levantando o número de habitantes, sua posição no domicílio e sua escolaridade em todos os municípios do Brasil.

O IBGE realiza também, o Censo Agropecuário, que pesquisa informações sobre os estabelecimentos rurais tais como sua área, produção, utilização de insumos e equipamentos, sendo o último referente ao período 1995-96. Os Censos permitem a abertura de informações detalhadas temática e territorialmente, sendo possível, por exemplo, a recuperação de dados para cada um dos 5.561 municípios brasileiros. Ainda no que diz respeito às características da população no que se refere a sexo, idade, rendimento, educação, condições de habitação, atendimento por saneamento básico, o IBGE realiza, anualmente, a Pesquisa Nacional por Amostra de Domicílios - PNAD, cujas informações são detalhadas para os Estados como um todo e para as Regiões Metropolitanas.

Até 1985 eram realizados também os Censos Econômicos, coletando informações sobre a indústria, o comércio e os serviços. Desde então, o IBGE vem se dedicando ao desenvolvimento e aprimoramento de pesquisas econômicas de caráter amostral. Para auxiliá-la nesse processo foi contratado um trabalho de consultoria do órgão de estatísticas do Canadá. Como um dos primeiros passos na montagem dessa nova estrutura, foi realizado, em 1995, a pesquisa Censo Cadastro, com o objetivo de montar uma base de informações sobre as empresas numa nova classificação de atividades - a Classificação Nacional de Atividades Econômicas - CNAE -, compatível com a International Standard Industrial Classification of All Economic Activities - ISIC, $3^{\mathrm{a}}$ revisão, das Nações Unidas, que lhe permitisse realizar anualmente esses levantamentos.

Estes trabalhos referentes ao desenvolvimento, aprimoramento e disseminação do uso de classificações de atividades e produtos, diga-se de passagem, continuam acontecendo até hoje na Comissão Nacional de Classificação - CONCLA, que é coordenada pelo IBGE, deles tendo resultado, por exemplo, a CNAE Fiscal, utilizada pelos áreas públicas responsáveis pelo controle da arrecadação. Os efeitos desse esforço já podem ser observados, por exemplo, com a Pesquisa Industrial Anual - PIA, com a Pesquisa Anual de Comércio - PAC, com a Pesquisa Anual de Serviços e com a Pesquisa Anual da Indústria da Construção - PAIC.

Se as pesquisas amostrais trazem consigo as vantagens dos menores custos e do menor tempo necessário ao processamento e divulgação de seus resultados, por outro, trazem um problema para um país de dimensões continentais como o Brasil: a ausência de informações sobre o que se passa na estrutura das economias locais e na distribuição espacial da atividade econômica. É aqui que fica evidente a importância dos registros administrativos como fontes alternativas de informação, principalmente sobre a economia, mas não só sobre ela. Esses registros, como já foi dito anteriormente, não são produzidos com o fim principal de serem utilizados como estatísticas socioeconômicas, mas para permitir o acompanhamento das atividades das instituições que os elaboram ou para o controle da população.

No entanto, dados desagregados espacialmente como os referentes à arrecadação de impostos, valor adicionado fiscal, emprego formal, estrutura de telecomunicações, consumo e consumidores de energia, estrutura de atendimento à saúde, matrículas por nível de ensino, quando corretamente traba- 
lhados e analisados, podem fornecer pistas importantes sobre os caminhos que estão trilhando a economia e a sociedade em regiões determinadas.

Cabe aqui ressaltar que, com o recente processo de privatização de empresas estatais, dificuldades vêm sendo colocadas para o acesso a algumas dessas informações, sob o pretexto de que elas seriam estratégicas para os seus negócios. Na verdade, os contratos de concessão dessas atividades são omissos sobre a questão, sinalizando que ela merece revisão pelo poder concedente para que esses dados possam novamente ser utilizados.

Pesquisas de informações municipais, como a Pesquisa Municipal Unificada da Fundação SEADE, aplicada no Estado de São Paulo, e a Pesquisa de Informações Básicas Municipais do IBGE, referente a todo o Brasil, baseiam-se em registros dessa natureza mantidos pelas prefeituras. Referimo-nos, até o momento, às estatísticas chamadas estruturais, que são as que procuram revelar as alterações por que vão passando a economia e a sociedade num período mais longo de tempo. São produzidas também estatísticas de natureza conjuntural, necessárias para o acompanhamento e para a correção, quando necessária, dos movimentos de curto prazo por que passa a economia e também para o acompanhamento dos resultados da aplicação de determinadas medidas de política econômica. Neste último caso, a produção acontece não só nas agências públicas, mas também em um número significativo de organismos privados, especializados em pesquisas ou não.

O IBGE é responsável por levantamentos como a Pesquisa Mensal de Emprego - PME, Pesquisa Industrial Mensal - Produção Física-PIM-PF, Levantamento Sistemático da Produção Agrícola LSPA e Índices de Preços ao Consumidor. Pode-se também encontrar e analisar informações produzidas, por exemplo, pela Fundação Getúlio Vargas FGV e pelo Departamento Intersindical de Estatísticas e Estudos Socioeconômicos - DIEESE, no que diz respeito ao comportamento de preços, pela Federação das Indústrias do Estado de São Paulo - FIESP sobre o nível de atividade industrial, pela Federação do Comércio sobre as vendas do varejo na Grande São Paulo.

No Estado de São Paulo o organismo público responsável pela produção, tratamento e análise de informações socioeconômicas é a Fundação Sistema Estadual de Análise de Dados - SEADE. Esta instituição é a herdeira de outras que tem se dedicado à produção de informações sobre o Estado de São Paulo desde março de 1892, quando foi criada a Repartição de Estatística e Arquivo do Estado de São Paulo, vinculada à então Secretaria do Interior, desenvolvendo hoje uma gama extensa de pesquisas sobre a realidade paulista.

No que diz respeito à demografia, a Fundação SEADE coleta em todos os cartórios de registro civil dados sobre nascimentos, óbitos e casamentos que permitem inferir informações sobre a dinâmica populacional do Estado. Desses dados irão resultar, por exemplo, as estimativas de população que são fundamentais para o desenho e acompanhamento de políticas públicas em áreas com saúde, educação e previdência.

Decorrem também informações sobre as principais causas de morte, que podem ser analisadas regionalmente ou de acordo com o perfil etário da população, orientando ações no sentido da redução daquelas causas que podem ser evitáveis. No que se refere às pesquisas primárias, ela realiza, em primeiro lugar, a Pesquisa de Emprego e Desemprego PED, feita desde 1985 em parceria com o DIEESE, coletando dados sobre desemprego, nível de ocupação e rendimento na Região Metropolitana de São Paulo. Realiza também a Pesquisa de Condições de Vida - PCV , cuja primeira edição ocorreu inicialmente na Região Metropolitana de São Paulo entre junho e agosto de 1990, coletando informações sobre os temas: domicílio; família e morador; habitação e patrimônio familiar; utilização de serviços de saúde; educação; inserção no mercado de trabalho e beneficios do trabalho e rendimentos.

A segunda PCV aconteceu entre maio e outubro de 1994, passando a referir-se à Região Metropolitana de São Paulo e a todos municípios 
com população urbana superior a 80 mil habitantes. Esta pesquisa levantou informações sobre os temas referidos anteriormente e também sobre meios e custos de transporte e à ocorrência de acidentes de trabalho e doenças profissionais. A última PCV foi a campo em 1998.

Já no que se refere às pesquisas econômicas de natureza estrutural, a Fundação SEADE realiza a Pesquisa da Atividade Econômica Paulista - PAEP, sendo que a primeira delas foi a campo em 1997, coletando informações referentes a 1996 sobre a indústria de transformação, comércio, indústria da construção, bancos e serviços de informática. Este levantamento trouxe importantes inovações em sua metodologia, já que a PAEP pesquisa nas empresas não só as tradicionais informações referentes à produção e emprego, tais como as necessárias ao cálculo do valor adicionado, que mede o que foi efetivamente produzido pelo agente econômico, pessoal ocupado e valor dos salários.

Ela investiga também o modo como as empresas que atuam no Estado de São Paulo estão se inserindo no chamado processo de reestruturação produtiva, importante para os ganhos de qualidade e produtividade necessários a garantir a competitividade dessas empresas não só no mercado nacional, mas também no externo. Entre as questões deste bloco estão, por exemplo, as referentes ã produção e utilização de inovações tecnológicas de produtos e processos e utilização de tecnologia da informação. A pesquisa permite também que seja observada a distribuição espacial dos fenômenos investigados, as estratégias de localização das empresas, os mercados por elas articulados.

A PAEP deve ir novamente a campo em 2002, coletando dados sobre 2001 para a indústria de transformação, comércio, indústria da construção, serviços, bancos e sistema financeiro. Como resultado da experiência adquirida pela Fundação SEADE com a realização da PAEP, ela foi contratada pelo MEC para a produção, em todos os Estados brasileiros, da Pesquisa da Atividade Econômica Regional - PAER, que buscou informações para subsidiar o desenvolvimento do Programa de Expansão da Educação Profissional - PROEP, que procura reestruturar em profundidade o ensino técnico profissionalizante no Brasil. A PAER levantou informações para a indústria e alguns segmentos de serviços sobre, por exemplo, a demanda de mão de obra técnica, pessoal ocupado, requisitos para a contratação, inovação tecnológica, localização industrial.

Até o momento discutimos questões relacionadas com a natureza e a produção de estatísticas socioeconômicas. Agora passaremos a abordar a vertente da disseminação. Antes porém é preciso falar um pouco da história recente da Fundação Seade e do IBGE em uma primeira tentativa de sistematizar os acontecimentos que envolveram essas duas instituições nas últimas décadas, ainda que de forma incompleta e possivelmente com equívocos, mas com o intuito de estimular o debate e assim ampliar o conhecimento sobre o assunto.

A crise do estado brasileiro, que começa a delinear-se no final dos anos 70 e instala-se com toda a força na década seguinte, atinge as agências de estatística de duas formas. A primeira, em ordem cronológica, foi através da deterioração das finanças públicas e a conseqüente perda da capacidade do governo em custear os gastos da máquina pública $\mathrm{e}$ realizar os investimentos necessários para atender a demanda por serviços públicos como os de saúde e educação e a manutenção e expansão da infraestrutura.

Ao financiar o crescente buraco nas contas públicas por meio da emissão de moeda, o governo provoca a explosão da inflação e cria um cenário de grandes incertezas. O resultado é o enfraquecimento e desorganização das ações de governo. O planejamento como instrumento para atacar as questões nacionais, regionais ou locais vai sendo progressivamente abandonado (desacreditado), na mesma proporção em que o governo volta-se para atacar o curto prazo, o imediato, na tentativa de controlar uma situação que parece ser cada vez mais emergencial. Essa reviravolta no estado das artes têm grande 
impacto nas agências públicas de estatística, seja por colocar parte da sua agenda de produção, aquela voltada para o planejamento, subitamente em relativo desuso, seja pela diminuição dos recursos do tesouro a elas destinados.

No interior das agências os desafios multiplicam-se. De um lado, elas também têm de administrar o dia a dia, pois a falta de recursos vai obrigá-las a fazer escolhas, suspender planos e atividades. De outro, pela própria natureza da produção das estatísticas socioeconômicas não era possível reverter rapidamente sua agenda de produção de modo a dar conta de medir os novos processos sociais. Lembremo-nos que esse tipo de informação resulta de um recorte da realidade feito do ponto de vista do analista. Para fazer isso ele precisa identificar, estudar e entender o novo fenômeno que se instala (o que pressupõe uma certa durabilidade do mesmo) e desenvolver um método adequado para sua aferição. A necessidade de tempo, a impossibilidade do imediato é, portanto, intrínseca ao processo de produção das estatísticas socioeconômicas.

Outro aspecto importante é que o processo de decisão sobre as informações a serem produzidas, era centrado muito fortemente dentro das próprias instituições. Se isso reforçava a desejada autonomia técnica que esses órgãos necessariamente devem perseguir, trazia rigidez no momento de absorver demandas externas e desatenção quanto ao fato de que naquela hora carecia também valorar os dados de que se dispunha, especialmente junto à máquina de governo e aos segmentos mais representativos de usuários da sociedade. Caberia apontar as dificuldades para, no curto prazo, montar pesquisas ou adequar registros administrativos para medir os novos fenômenos sociais e econômicos e procurar expor o quanto as informações já existentes eram capazes de explicar a realidade deixando claro seus limites, mas ao mesmo tempo explorando ao máximo seu significado e demonstrando como elas poderiam ser melhor utilizadas.

A conjunção desses fatores: a necessidade de novos dados socioeconômicos por parte do governo e outros segmentos sociais, uma certa inflexibilidade das agências em aceitar novos pedidos e a insuficiência de suas ações no sentido de melhor divulgar o potencial explicativo das informações disponíveis vai causar uma série de fricções e mal entendidos entre ofertantes e demandantes de informações. Não é inusitado, portanto, que logo comecem a surgir críticas, sobretudo na máquina de governo, onde estão seus principais, mais articulados e poderosos usuários. Esgarça-se a legitimidade das agências perante esses atores e isso vai dificultar o seu êxito na crescente disputa que se estabelece entre os órgãos públicos pelo volume minguante dos recursos do caixa do tesouro. Os dirigentes públicos pressionados por questões até então desconhecidas, obrigados a governar de afogadilho, não vêem (porque não conseguem formular com clareza suas demandas ou porque não entendem como se produz a informação socioeconomica) ou não compreendem (porque elas não estão suficientemente explicadas) como as informações já produzidas pelas agências podem servir-lhes para ajudar a tomar suas decisões no dia-a-dia.

O segundo golpe contra as agências vem logo no início dos anos 90. O triunfo do modelo capitalista sobre o socialista instaura em definitivo a discussão do papel do estado em países como o Brasil. O planejamento e a ação de estado como condutora das transformações sociais, pelos seus inegáveis vínculos com o modelo derrotado, serão cada vez mais desprezadas em prol do mercado erigido pelos novos ventos liberalizantes em avatar que guiará a sociedade para um mundo melhor.

Não é por acaso que no governo Collor o IBGE foi seriamente atingido. Com os cortes orçamentários, o aviltamento dos salários que provoca a perda de técnicos qualificados para a iniciativa privada e a não realização de concursos públicos para repor os seus quadros esvai-se boa parte do conhecimento científico acumulado pela instituição. Mais recentemente, as alterações na legislação referente às regras de aposentadoria do servidor público levam técnicos a abandonarem seus traba- 
lhos precocemente, fenômeno que também pode ser observado em muitas outras instituições federais de pesquisa e em universidades. Um dos reflexos destes momentos conturbados foi o fato de não ter ido a campo o Censo Demográfico de 1990, que era realizado regularmente a cada dez anos desde 1940, e que só a duras penas foi feito em 1991.

A reconstrução do IBGE começou a ser gestada nos anos seguintes com um movimento no sentido da busca da modernização das pesquisas realizadas, incorporando-se, por exemplo, modernas técnicas de amostragem e buscando-se a colaboração de organismos internacionais de renome, caso do Statistics Canada, como já foi citado anteriormente. Essas inovações cobraram seu preço, pois, como também já foi mencionado, é necessário tempo para a estabilização de uma nova metodologia. Houve assim um momento em que entre a realização dos levantamentos e a divulgação dos resultados existia um intervalo grande de tempo, mas esta fase já está superada. Exemplo disso é a Pesquisa Industrial Anual, que desde o levantamento de 1996, a cada ano vem conseguindo estreitar o espaço de tempo entre as datas de levantamento e divulgação.

Paralelamente, outras providências como a reposição de quadros através de concurso público, recuperação da infraestrutura e aquisição de novos equipamentos vão contribuir para acelerar a recuperação do órgão e colocá-lo, já há alguns anos, em um novo ciclo virtuoso. Todo esse processo foi realizado através do aporte de dinheiro público, injetado diretamente no orçamento do órgão. O IBGE faz parte da administração federal e seu pessoal está sujeito às regras do funcionalismo público. Seu presidente, Sérgio Besserman, declarou no primeiro semestre de 2001 que os recursos próprios obtidos com a venda de produtos e serviços significavam somente cerca de $3 \%$ das receitas totais do órgão.

Já na Fundação Seade as crises ocorreram em momentos distintos no tempo e as saídas encontradas percorreram outros caminhos. Criada no final de 1978, sucedeu um órgão criado na última década do século XIX, a Repartição Estadual de Estatística, que por sua vez passou por inúmeras transformações e mudou várias vezes de nome ao longo dó século XX. Logo no primeiro ano de sua existência, já no governo de Paulo Maluf, enfrenta sua primeira turbulência, na qual um corte no seu orçamento obriga à extinção de uma diretoria e à demissão de cerca de um quinto de seus funcionários. Até meados dos $\operatorname{anos} 80$ a instituição dedicou-se basicamente à realização de levantamentos e análises de informações que já eram tradicionais nas instituição, como aquelas referentes a população ou originárias de fontes secundárias - os registros administrativos. O ganho mais significativo, em termos da ampliação de sua agenda de produção ocorrido neste período foi o início da PED - Pesquisa de Emprego e Desemprego em 1985 que agregou um novo campo de investigação na instituição, o mercado de trabalho na Região Metropolitana de São Paulo, e apresentou um metodologia inovadora construída que pela primeira vez levava em conta as formas e relações de trabalho que vigiam no país.

A partir de 1987, na gestão de Orestes Quércia como governador do estado, a Fundação Seade atravessa uma espécie de quarentena, no qual se assiste ao aviltamento dos salários e a uma degradação material do prédio e das condições de trabalho. Apesar disso, em 1990, a instituição passa a inquirir sobre como vive a população na Região Metropolitana do Estado, novamente com expressivos avanços metodológicos, especialmente na conceituação da pobreza, por meio da PCV- Pesquisa de Condições de Vida.

Um novo ciclo tem início em 1991, no governo Fleury, no qual a injeção de recursos adicionais do tesouro paulista propicia a adoção de uma série de medidas que vão desde a recomposição salarial, investimentos em setores chaves como a informática (nesse caso com apoio fundamental, através de financiamento, da FAPESP - Fundação de Amparo a Pesquisa no Estado de São Paulo), e o aporte de novos conhecimentos com a contratação de consultores oriundos de diversas universidades. 
A Fundação Seade recupera sua auto estima e apoiada no que havia conseguido, apesar de tudo, preservar da etapa anterior: a imagem de seriedade $\mathrm{e}$ competência a garantir a credibilidade de suas informações, põe em dia sua produção e gesta novas pesquisas como a PAEP - Pesquisa da Atividade Econômica Paulista e a PMU - Pesquisa Municipal Unificada, para acompanhar as transformações em curso no Estado de São Paulo. Esse processo culmina com a realização de um concurso público no final de 1994 que incorpora novos técnicos aos quadros da instituição, em vagas antes ocupadas por pessoas contratadas como prestadoras de serviço. Tudo indicava que a Fundação SEADE estava pronta para continuar na sua trajetória de consolidação de suas atividades e ampliação de suas linhas de pesquisa , em suma pronta para um novo salto, o segundo em menos de quatro anos.

Porém, em 1995, novos fatos vão abortar esse caminho. O recém empossado governo Covas herda as contas públicas com um rombo enorme e, para fazer frente a essa situação financeira extremamente grave, corta em $30 \%$ o orçamento de vários órgãos públicos. O da Fundação Seade não será exceção e permanecerá congelado nesse patamar pelos quatro ou cinco anos seguintes. Colocou-se então o dilema: a Fundação SEADE deveria encolher para adaptar-se ao orçamento ou buscar alavancar recursos próprios? No curto prazo (de abril a novembro de 1995), contudo, medidas drásticas como a demissão ou a colocação compulsória em licença sem vencimentos de perto de 150 pessoas, redução de jornada de trabalho foram necessárias para equilibrar receitas e despesas.

A opção tomada, na época, enveredou pelo segundo caminho e, em cerca de dois anos, uma série de projetos ancorados em contratos foi celebrada, principalmente, com secretarias e empresas do governo do estado e com ministérios da União garantindo a sobrevivência da instituição. O sucesso alcançado nesse modelo de financiamento pode ser constatado pela evolução da proporção de recursos próprios sobre as receitas totais. Ela foi evoluindo constantemente durante os anos seguintes para chegar a surpreendentes $40 \%$ em 2000 .

É importante notar que os recursos, em bora vinculados a prestação de serviços de levantamento, tratamento e análise de informações estatísticas, continuam sendo oriundos dos cofres públicos, pois saem dos orçamentos dos órgãos governamentais. Temos aqui uma nova situação caracterizada: parte da produção de informações socioeconômicas pela Fundação SEADE não obedece mais a decisões internas, mas é negociada, na prática, pela necessidade de fazer caixa. Mais, ela não é feita de modo científico ou orgânico no sentido de atender as necessidade que o governo têm de conhecer a realidade paulista para pautar suas ações, mas apenas pela soma isolada dos mesmos interesses, o que não é garantia de demandas harmônicas ou coerentes do ponto de vista do uso dos recursos públicos e da geração de conhecimento. Também não participam da decisão sobre quais informações deveriam ser produzidas outros segmentos importantes da sociedade como: órgãos de classe (sindicatos e federações de patrões e empregados), pesquisadores e cientistas, empresas de consultoria, organizações não governamentais etc., embora aqui, mesmo que houvesse a vontade, os meios de assegurar essa participação (de ouvir esses segmentos) teriam de ser construídos.

Quais são os efeitos desse novo padrão de financiamento sobre a disseminação? Para entender melhor as conseqüências sobre o acesso às informações é preciso recuar um pouco no tempo para examinar como as coisas aconteciam antes da grande revolução tecnológica na área. A princípio, a informática na sua arquitetura de mainframes nas décadas de 60, 70 e meados de 80 e da microinformática assentada em estações de trabalho isoladas da metade dos ano 80 até o começo dos 90, embora traga inegáveis progressos no armazenamento e processamento da informação não muda substancialmente a disseminação.

O meio impresso permanece como a forma preponderante de disponibilizar as informações com 
as limitações a ele, como meio físico, inerentes e que são a decisão de quem terá acesso à publicação e sob que condições, as tiragens restritas e insuficientes etc. Por outro lado, as informações adicionais que não estavam publicadas eram objeto de negociação mais duras ou mais amenas, exitosas ou não, com as áreas que as produziam, já que tanto o papel como o disquete permitiam, via armazenamento em espaço particular, a propriedade do indivíduo ou grupo restrito, através da barreira ao acesso. Nessa época havia a figura que se convencionou chamar de "dono(a) do dado".

A situação começa a mudar em meados da década de 90. Inicialmente com o advento das novas redes interligando os microcomputadores com características bastantes distintas daquelas mais antigas ligadas a mainframes e que operavam programas específicos desenvolvidos exclusivamente para esta ou aquela aplicação. As novas redes operam com softwares existentes no mercado e aqueles que dela fazem parte dividem algumas áreas de trabalho em comum. Esse espaço comunitário parece ter tido um efeito pedagógico sobre os que produzem informações, ensinando-os a partilhá-las, lendo e trocando arquivos. Fundamentalmente, aclara-se a percepção que o diferencial que mantêm ou não cada técnico na sua posição não é a mera posse da informação, mas sim o conhecimento do campo, a arte de produzi-la e o domínio de seu significado.

Logo após surge a Internet, a princípio tímida e restrita a pequenos grupos de usuários e com baixo volume de informações. Porém com sua impressionante dinâmica revelada pelas taxas exponenciais de crescimento tanto de usuários como de páginas, a Internet logo torna-se o principal meio de disseminação de dados para as agências públicas. Isso pelas particularidades dos usuários da informação socioeconômica. A natureza destas é de uma medida abstrata de determinados aspectos da realidade, cuja escolha e importância é definida pelo ponto de vista de quem a está medindo e na qual não se enxergam indivíduos, mas sim grupos reunidos, não por suas interelações sociais, mas por determinadas características comuns circunstanciais ou definitivas (renda, idade, cor, posição na ocupação, desempregado etc).

"O conhecimento estatístico tem suas raizes no racionalismo do século XIX, do qual ele compartilha suas caracteristicas: exterioridade do sujeito em relação ao objeto; independência recíproca; possibilidade de conhecimento do objeto. Os conceitos pelos quais os homens apreendem o mundo aparecem como propriedades da realidade, ou pelo menos aproximações que, com o progresso ajudando, se tornam mais e mais exatas." (Besson, 1995).

Seu uso assim é restrito em primeira instância, às camadas da população com acesso aos níveis mais elevados do sistema educacional. E ainda dentro desta camada àqueles que se especializaram em algum tipo de atividade que exija esse tipo de informação. Os principais usuários das informações, produzidas pelas agências públicas, são o próprio governo, pesquisadores, professores, estudantes e empresas de consultoria e de pesquisa de mercado. Estes usuários de modo geral tiveram acesso precoce à Internet e para eles a questão do acesso aos dados, pelo menos quanto ao aspecto de meios para a navegação, nunca chegou a se constituir em grande obstáculo.

Com a Internet os produtores de estatísticas perdem inteiramente o controle sobre quem irá acessá-las. A distribuição de publicações por meio de mailing-lists selecionados perde sua função de fazer chegar as informações preponderantemente a círculos seletos e a determinadas pessoas, com a conseqüente atribuição de conhecimento antecipado e privilegiado e, portanto, do poder que pudesse ser extraído desse conhecimento. Essa distribuição tem agora apenas a função de divulgação de chamar a atenção de pessoas e grupos entendidos como importantes que determinadas informações já estão disponíveis. Pela Internet simpatizantes e adversá- 
rios poderão ter acesso a elas sem nenhum tipo de autorização ou negociação prévia.

O principal desafio enfrentado agora, para a disseminação de informações estatísticas na Internet parece ser a organização dessa imensa e crescente quantidade de dados que vai sendo disponibilizada. É bom esclarecer que não se está falando da procura pelas páginas que contêm as informações, hoje razoavelmente atendida pelos diversos mecanismos de busca existentes (Yahoo, Altavista, etc.), mas da arrumação, do ordenamento desse tipo de informação dentro de páginas como a do SEADE e do IBGE, encontradas em tabelas ou banco de dados.

A dificuldade é que a linguagem para recuperação de dados estatísticos encontra-se bem menos desenvolvida do que para a informação textual. Enquanto nesse último caso a experiência já secular na catalogação e indexação dos acervos das bibliotecas possibilitou um crescente e constante aperfeiçoamento dos mecanismos de recuperação, que começaram com o sistema decimal e evoluíram até chegar à linguagem controlada e seus thesaurus, para os dados estatísticos ainda não se dispõe de algo semelhante. Para este, ser iniciado no assunto de que tratam os dados é ainda uma vantagem fundamental, já que as variáveis estão agrupadas em temas, às vezes em sub-temas e quase nunca em assuntos, dentro de tabelas em produtos com o nome das pesquisas sob as quais são construídos (CENSO, PNAD, PED, PME, etc). O leigo, aquele que não domina as especificidades e peculiaridades dos agrupamentos de dados ou desconhece o conteúdo dos produtos, tem de enfrentar a tarefar de navegar longamente pela página, tendo como aliados o bom senso e a sorte e como inimigos, além do azar, as armadilhas que, inconscientemente, é verdade, lhes prepara o subjetivismo de quem organiza a página.

Outro ponto interessante a ser colocado na questão da disseminação diz respeito a entrada em cena nas instituições em que o financiamento já não é feito diretamente pelo tesouro público, como no caso da Fundação SEADE, de um novo ator nesse processo. Se antes a produção, cumprida as etapas de levantamento e consistência, deveria por direito incontestável ser posta à disposição da sociedade já que o recurso que possibilitou sua obtenção era notoriamente (sem contestação) público, agora existe uma nova instância intermediária, o "cliente", aquele que encomendou e pagou pela informação.

Embora, como já se viu, esses "clientes" sejam órgãos públicos, a encomenda de dados obedece às necessidades internas de determinado órgão, cuja finalidade não é como a da Fundação SEADE, produzir e disponibilizar informações, mas qualquer outra dento das diversas áreas de atuação governamental. Assim a informação não será vista, forçosamente, nesses órgãos como um fim em si, mas como insumo para conhecer melhor a realidade onde opera, embasar projetos ou tomar decisões. Portanto, não há necessariamente, e dentro de sua lógica interna não há razão para que haja, nenhum compromisso intrínseco com a colocação dessas informações para a sociedade.

Surge assim o paradoxo: o financiamento da Fundação SEADE, ainda que dividido entre os tesouros estadual, federal e municipais e os caixas dos órgãos da administração indireta, continua sendo inquestionavelmente público. As vias pelas quais esse dinheiro chega tornaram-se indiretas, mas de fato permanecem sendo resultado da contribuição de toda a sociedade. Porém a informação já não está, por direito, acessível a todos, é preciso agora negociar com seu proprietário, aquele que comprou através de financiamento, e será dele, desse órgão financiador a decisão final sobre o destino da informação, se para toda a sociedade ou para uso interno.

Discutir a agenda de produção das agências públicas de estatística e a disseminação de suas informações interessa a todos aqueles que delas se utilizam. No entanto, asseverar que todos os interesses de seus usuários estejam representados na produção das agências e, ao mesmo tempo, equacionar a questão do financiamento dessa produção é algo para o qual ainda não existe um modelo. 
O avanço da democracia pressupões grupos sociais fortes e organizados na defesa de seus interesses e para reivindicá-los é preciso embasá-los com representações da realidade, com dados socioeconômicos, com o conhecimento oferecido pela ciência. No tocante ao financiamento das agências, é difícil imaginar que ele não continue a cargo do setor público. Produzir informações socioecônomicas é tarefa de custos elevados e que não podem ser recuperados com a venda dos seus resultados. Não é crível imaginar que pesquisas como o Censo Demográfico do IBGE ou a PAEP do Fundação Seade possam ser pagas com a comercialização do conhecimento que geram e, onde não há lucro, não há interesse da iniciativa privada. É preciso entender que os benefícios que os dados socioeconômicos trazem são de outra natureza. Eles permitem conhecer as questões sociais e indicam o melhor caminho para lidar com elas. Seu retorno vem na forma do progresso social e, este é (ou deve ser), por definição, o objetivo de qualquer governo.

\section{REFERÊNCIAS BIBLIOGRÁFICAS}

BARRETO, Aldo de Albuquerque. A questão da informação. São Paulo em perspectiva, São Paulo, vol. 8, n. 4, pp. 3-8, out./dez., 1994.

BESSON, Jean-Louis. A ilusão das estatísticas. São Paulo: UNESP, 1995

PORCARO, Maria Rosa. A informação estatística oficial na sociedade da informação: uma (des)construção. DataGramaZero - Revista de Ciência da Informação, Rio de Janeiro, vol. 2, n. 2, 2001. Disponível na Internet em: www.dgzero.org.

SENRA, Nelson de Castro. Política de informação estatística, instrumento de regulação para/pela coordenação. Rio de Janeiro: IBGE, 2000. (Texto para discussão). 